\title{
Aristóteles y la prueba de que el ser no es un género (Metafísica III 3)
}

\author{
MARCO Zingano \\ Departamento de Filosofia \\ Faculdade de Filosofia, Letras e Ciências Humanas \\ Universidade de São Paulo \\ mzingano@usp.br
}

\begin{abstract}
Resumen: En este artículo se abordan diversos aspectos de la prueba que Aristóteles presenta en Metafísica III 3, según la cual el ser no es un género. En particular, procuro delimitar la dimensión bastante restringida de su campo de aplicación, tomando en cuenta sus premisas en relación con las condiciones de una buena definición según el estándar de género y diferencia específica, y también trato de comprender la recepción poco entusiasta que tuvo ya en la Antigüedad, comenzando con Alejandro de Afrodisias.
\end{abstract}

Palabras clave: homonimia, género, ser, principios generales

\begin{abstract}
In this paper, my aim is to investigate some features of the way in which Aristotle argues for his basic tenet that being is not a genus in Metaphysics III 3. The argument proves to be rather restricted, as it operates with premises specifying very special conditions for a good definition in accordance with the genus-plus-differentia pattern. It is argued then that this strong dependence on premises stemming from very specific philosophical schools accounts for its rather mitigated reception already in Antiquity, beginning with Alexander of Aphrodisias.
\end{abstract}

Key words: homonymy, genus, being, general principles

Como es bien sabido, en el tercer libro de la Metafísica, Aristóteles presenta una prueba de que el ser no es el género supremo de todo lo que es, como tampoco el uno lo es. Esta prueba parece gozar de una posición central, pues sirve de fundamento a la tesis básica de la metafísica aristotélica con respecto a la difusión originaria e irreductible del ser en sus diferentes categorías. En este ensayo deseo analizar las pretensiones de esta prueba y el modo como Aristóteles intenta alcanzar su objetivo.

La prueba se encuentra en III 3 998b22-28, en lo que se ha convenido en llamar la séptima aporía. He aquí el texto:

No es posible ni que el ser ni que el uno sean un género único de los seres, pues, por un lado, las diferencias de cada género necesariamente son y 
cada una es una; por otro lado, es imposible que las especies del género o que el género, aparte de sus especies, se prediquen de las diferencias mismas, de suerte que si el uno o el ser fueran un género, ninguna diferencia sería un ser ni sería una. Sin embargo, si entonces el ser y el uno no son géneros, tampoco serían principios si los géneros fueran principios.

No hay grandes problemas con este texto. El manuscrito $\mathrm{A}^{\mathrm{b}}$ simplifica la primera frase así: "no es posible ni que el uno ni que el ser sean un género"; el manuscrito E, por su lado, crea un paralelismo en las líneas 24-26: "o que las especies aparte del género o que el género

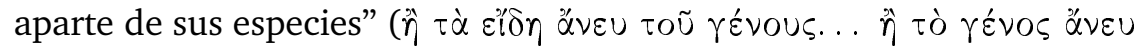

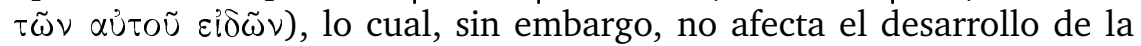
prueba. ${ }^{1}$ La segunda parte de la explicación se refiere al género sin sus especies porque, como se dice en la primera, si las especies del género no se predican de las especies, es muy posible que el género tampoco se predique, ya que de manera subrepticia traería consigo sus especies; la cláusula busca evitar esta posibilidad y con ello enfatiza que el género es, de suyo, lo que no se predica de las diferencias. ${ }^{2}$ La última frase necesita una interpretación. Literalmente nos dice que si es verdad que los géneros son principios, entonces el ser y el uno no son principios porque no son géneros. A todas luces, tal interpretación es demasiado endeble para asegurar el resultado esperado, pues el ser y el uno podrían ser principios, incluso no siendo géneros, siempre y cuando elementos que no son géneros sean principios (lo que, según parece,

${ }^{1}$ Sobre todo porque, como observa W.D. Ross, "el primer aspecto [i.e., la especie no se predica de la diferencia] se plantea aquí por mor de la completud, aunque sea irrelevante para lo que Aristóteles quiere probar" (Aristotle's Metaphysics, vol. I, p. 235).

${ }^{2}$ Sin embargo, el texto permite otra interpretación, defendida por Alejandro: el género no se predica de sus diferencias cuando éstas se consideran aparte de las especies, esto es, las especies no están comprendidas en las diferencias (205, 2930). En esa lectura, la distinción estriba en que "animal" no se predica de "terrestre bípedo", sino de "animal terrestre bípedo", es decir, del hombre. Hermann Bonitz sigue a Alejandro: "genus non praedicatur de suis differentiis, si hae differentiae per se spectentur, seiunctae ab iis, quae inde efficiuntur, speciebus" [el género no se afirma de sus diferencias si se las mira por sí mismas, separadas de esas especies que de ahí se originan] (Commentarius in Aristotelis Metaphysicam, Olms, 1992,

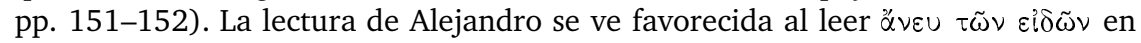

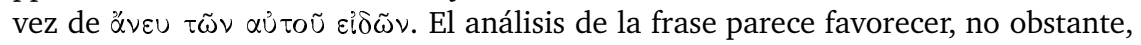
la lectura que ofrecí (adoptada por Ross en su comentario: "ni pueden las especies predicarse de sus propias differentiae, ni puede el género, si se toma aparte de sus especies, predicarse de sus differentiae" (p. 235)). El mencionado paralelismo del manuscrito E refuerza esa lectura sintáctica.

Diánoia, vol. LV, no. 65 (Noviembre 2010). 
no se excluye en el argumento). Sin embargo, en la aporía anterior, directamente ligada a ésta, se formula el problema de saber si el principio o bien es el género, o bien son los elementos de que están constituidas las cosas. Desde el punto de vista de las cosas, los elementos que las constituyen parecen ser sus principios, lo que llevaría a tomar el elemento material como el principio último de todas las cosas; lo anterior implicaría la exclusión del género. Pero, desde el punto de vista de la definición, es decir, de la fórmula que muestra la esencia de una cosa, es el género lo que, ante todo, parece ser el principio de las cosas (pues, por lo menos - dice Aristóteles-, los géneros son principios de las especies, 998b8). ${ }^{3}$ Por otra parte, al tomar este último cuerno del primer dilema y pasar así a la séptima aporía, falta por saber si, estando los géneros identificados con los principios, son principios los géneros más altos o aquellos que lindan con los particulares. En la aporía anterior, la sexta, révos designaba a todo universal, al abarcar indistintamente los géneros y las especies; en la séptima, es preciso distinguir, dentro de los $\gamma \varepsilon ́ v \eta$, los géneros primeros, los más altos (en este caso, el ser y el uno), de los universales inmediatamente bajo los cuales encontramos a los individuos, esto es, a las ع’ôn o infimae species. La expresión

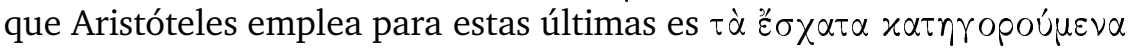

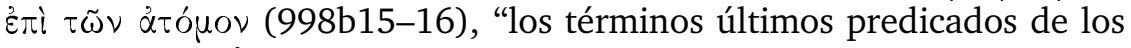
particulares". Éstos son los candidatos adecuados en la perspectiva aristotélica; el argumento en 998b22-28 busca obstaculizar la candidatura de los géneros superiores. En este contexto debe leerse la frase final "si los géneros fueran principios", es decir, acepto que los géneros asuman el dominio entero de los principios.

${ }^{3}$ En las últimas líneas de la sexta aporía, Aristóteles observa también que algunos pensadores, a saber, los platónicos, tratan manifiestamente el uno y el ser como géneros considerándolos elementos de las cosas, así como lo grande y lo pequeño

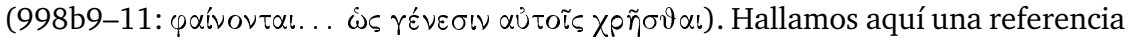
a las doctrinas no escritas de Platón sobre lo grande y lo pequeño. Aristóteles es muy tajante en este pasaje al observar: no es posible, con todo, tratar los principios al mismo tiempo como elementos y como géneros (998b11-12). La razón que aduce es que la definición mediante el género y la diferencia específica da como resultado una unidad, mientras que la definición con base en los elementos constitutivos redunda en una multiplicidad (por ejemplo, la casa es o bien un alojamiento para los bienes o las personas, o bien está hecha de ladrillos, tejas, madera: en ambos casos, el definiens es complejo, pero en el primero es uno, en tanto que en el segundo es múltiple). Esto debe servir de advertencia a quienes hoy buscan introducir elementos materiales en las definiciones de la esencia de algo. En $\Lambda$ 4, Aristóteles presenta la prueba de que principio y elemento son distintos, aunque ambos sean causas del ser (4 1070b22-27). 
El libro XI, en cuyos primeros capítulos se presentan los libros III, IV y VI con una redacción distinta, nos ofrece en 1 1059b31-34 el siguiente texto de la prueba en cuestión:

Si se postulara que éstos [i.e., el ser y el uno] son géneros, en la misma medida en que las diferencias participan necesariamente de ellos y ninguna diferencia participa del género, parece que no debe postularse que son géneros o principios.

De nuevo no hay ninguna variante importante del texto, salvo que en la apódosis figura un $\delta \varepsilon ́$, que desaparece en la paráfrasis del pseudo Alejandro y que motivó a Christ, en la edición Teubner, a proponer en su lugar un $\gamma \varepsilon$; sin embargo, como observa Jaeger en su aparato crítico, "frequens est usus particulae $\delta \varepsilon$ in apodosi apud Aristotelem" [es frecuente en Aristóteles el uso de la partícula $\delta \varepsilon ́$ en la apódosis], de modo que se puede mantener el texto transmitido por los manuscritos. En consecuencia, el ser no es un género, lo que deja la puerta abierta a la tesis metafísica con la cual se inaugura el aristotelismo; a saber, que el ser está originariamente difuso en las categorías, ellas mismas irreductibles unas a las otras en su calidad de géneros supremos. Aristóteles, como se sabe, deberá controlar este carácter difuso por medio

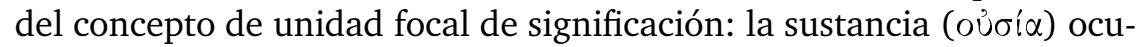
pa el lugar central y funciona a partir de allí como el ser primero (VII

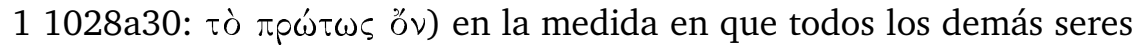
hacen referencia en sus definiciones (o en aquello que hace las veces de sus definiciones) ${ }^{4}$ a la sustancia. Al unificar, por medio de la significación focal, la difusión del ser en sus categorías, Aristóteles por fin estará en posibilidades de proponer una metafísica general, una ciencia de todo lo que es en cuanto que es, al mismo tiempo que sustenta la difusión originaria del ser en las diferentes categorías o géneros supremos del ser.

${ }^{4}$ Debe introducirse la cláusula de salvaguardia porque las categorías no podrían definirse propiamente si entendemos por definición un género común cualificado por una diferencia específica, pues la doctrina aristotélica de la difusión originaria precisamente impide recurrir a un género común, cualificado de manera diferente para cada categoría, aun cuando, obviamente, el ser se predique de todo lo que es. Las categorías son los géneros supremos y su diversidad es irreductible a una de ellas o a algo fuera de ellas. Por esta razón, los comentaristas del tratado de las Cate-

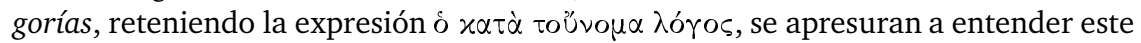

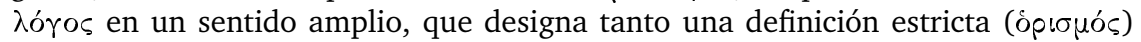
como una presentación general (iđorpạn': véase Ammonio in Cat. 17.11; Dexipo 20.30), ya que en el caso del ser y de sus categorías no puede haber una definición estricta, sino sólo una presentación general.

Diánoia, vol. LV, no. 65 (Noviembre 2010). 
Imposibilitar que se tome al ser como un género forma parte, entonces, de la estrategia aristotélica para sustentar su propia metafísica. En este sentido, en II 7 de los Segundos analíticos, Aristóteles vuelve a

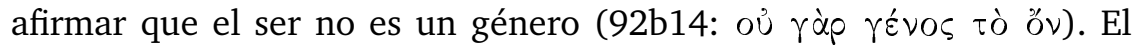
tema se aborda también en los libros centrales de la Metafísica. Como todo lo que es es y es uno, cada una de las categorías en que se divide el ser "inmediatamente es una, y también es" (Met. VIII 6 1045b5-6), no como si participasen del uno y del ser porque fueran sus géneros supremos, sino por el hecho de que el ser y el uno se difunden primero que nada en cada una de las categorías. De este modo, ni el ser ni el uno aparecen en sus definiciones. Si figuraran en una definición como género de algo, entonces la definición estaría mal formulada, pues el ser y el uno se atribuyen a todo lo que es (Tópicos IV 1 121a17-19) y, por consiguiente, no establecen distinción alguna. A veces, sin embargo, Aristóteles articula a partir de su propia posición su crítica al ser como género supremo y principio de todo lo que es. En efecto, en Metafísica VII 16 dirá que el ser no puede ser la esencia de las cosas (1040b18-

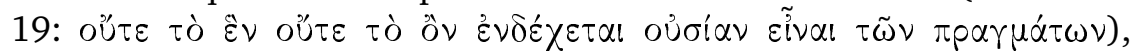
porque, como demostró en VII 13, ningún término universal puede ser sustancia; ahora bien, el ser es universal por excelencia, puesto que se dice de todo, y, por lo tanto, precisamente su naturaleza universal le impide ser la esencia de algo. ${ }^{5}$

El argumento no tuvo una recepción muy favorable. En su comentario sobre la afirmación de Segundos analíticos II 7 de que el ser no es un género, Jonathan Barnes señala que "Aristóteles ofrece en $\mathrm{Met}$ B 3, 998b22-7, un argumento malo y parco en favor de esto."6 De hecho, esta actitud negativa ya se había presentado en la Antigüedad. Alejandro de Afrodisias, al caracterizar el argumento central —a saber, que el género no se predica de sus diferencias-, escribe que parece ser

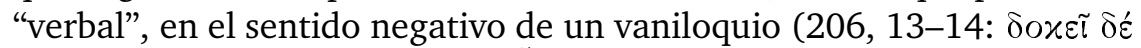

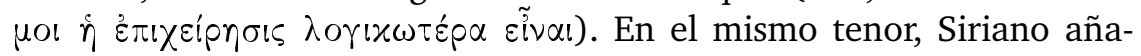
de que el argumento respecto de las diferencias es "confuso" (32, 40:

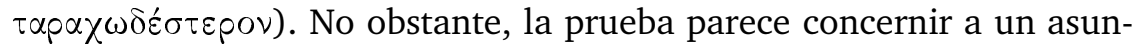
to crucial de la doctrina metafísica de Aristóteles; ¿cómo pudo haber errado tan manifiestamente a este respecto?

${ }^{5}$ En este último caso, sin embargo, depende de la prueba establecida en $\mathrm{Z} 13$ de que ningún universal es sustancia - prueba cuya fuerza puede ser tal que ponga en aprietos a la misma teoría aristotélica-. Sobre este asunto, véase en especial James Lesher, "Aristotle on Form, Substance, and Universals: A Dilemma".

${ }^{6}$ Aristóteles, Aristotle: Posterior Analytics, ed. J. Barnes, p. 215. 
Conviene examinar con mayor detenimiento lo que dice Alejandro, quien presenta dos argumentos para fundamentar su posición. En el primero, sostiene que hay casos en los cuales el género se predica de las diferencias; en efecto, si las tomamos como cualidades, podemos predicar de ellas el género "cualidad" del cual son las especies: "de este modo el género se predicaría de sus diferencias mismas" $(206,19)$. En el segundo argumento, concediendo en principio que puede suceder que el género próximo de algo no se predique de las diferencias - por ejemplo, cuando se trata de algo que es compuesto (como "animal" es "ser vivo sensible")—, si bien la diferencia es simple, aun así el género superior, la "sustancia", se predicaría del género y también de la cualidad. Sin embargo, ni uno ni otro argumento son convincentes. Con respecto al primero, Aristóteles no niega que las cualidades, tomadas en sí mismas, correspondan a un género; por el contrario, el mismo Aristóteles se refiere expresamente a los géneros de las diferencias, үévn $\tau \tilde{\omega} \nu \delta \iota \alpha \varphi \circ \rho \tilde{\omega} \nu$ (Met. VIII 2 1042b32), que serían diversos tipos de cualidades, por lo que todos ellos se deben subsumir en el género superior de la cualidad. No obstante, el meollo aquí es que el género de una especie no se predica de la diferencia que constituye aquella especie: "animal" no se predica de "bípedo", que es la diferencia originadora de la especie "hombre" cuando se aplica a "animal", pues el hombre es un animal terrestre bípedo. En cuanto al segundo argumento, obsérvese que Alejandro parece estar pasando de la diferencia que constituye una especie a las divisiones de un género, que en cierto sentido son diferencias de este mismo género por ser especies diferentes del mismo género: así, la sustancia se divide en corruptible e incorruptible, que de suyo son sustancias y pueden considerarse sustancias diferentes. Sin embargo, cuando en el género "animal", por ejemplo, opera la diferencia "terrestre bípedo", se origina una especie, la especie humana, sin que "terrestre bípedo" sea sustancia, aunque "hombre" y "animal" sí lo sean.

En cierto modo, parte de la discusión de Alejandro está contaminada por una dificultad que tenían en general los comentaristas antiguos con respecto al estatus de la diferencia. ${ }^{7}$ Alejandro parece titubear entre dos posturas. En la primera, las diferencias son cualidades y, en consecuencia, parecen incluidas en el rubro general de la categoría de la cualidad. En la otra, las diferencias se ordenan dentro de cada categoría a la que se aplican; así, cuando se aplican a la sustancia, ellas mismas son

${ }^{7}$ A este respecto, es muy provechosa la lectura de Simplicio, Comment. ad Cat. 97, 24-102, 10, pasaje que los traductores F. de Haas y B. Fleet titularon atinadamente como "Essay on the Differentia" (Simplicius —On Aristotle's Categories 5-6).

Diánoia, vol. LV, no. 65 (Noviembre 2010). 
sustancias. ${ }^{8}$ La dificultad estriba en que la diferencia es una cualidad, ya que cualifica de cierto modo el objeto sin tratarse, no obstante, de cualquier cualidad, pues es precisamente aquella que delimita el ser del objeto en cuestión. Se trata, en efecto, de un عióorolóv, como se dice en la Ethica Nicomachea X 3 1174b5 (cfr. Top. VI 6 143b7-9): una cualidad, sin duda, pero íntimamente ligada a la especie que determina como sustancia. Esta dificultad, mutatis mutandis, ya aparecía en el tratado de las Categorías. En ese tratado, al examinar la categoría de la sustancia, Aristóteles (o su autor) se ve llevado a diferenciar la sustancia, considerada ahí como el individuo, de las sustancias segundas —el género y la especie-, a las que considera, en relación con el individuo, cualidades que delimitan su ser - lo que hace de la sustancia segunda un tipo de cualidad, aunque no cualquier cualidad (cfr. Cat. 5 3b10-23)-.

Esto, sin embargo, es apenas una parte de la dificultad; el resto, propiamente, no lo expresa Alejandro, pero debe haberlo presentido. La prueba parece tener una pretensión enorme: fundar toda una metafísica, pero opera de un modo bastante intrincado y parece depender crucialmente de tesis muy específicas, cuya suposición en las premisas no esperaríamos; a saber, tesis muy precisas sobre la naturaleza de la definición y sobre el modo en que debemos proceder con respecto a la relación entre género, especie y diferencia. De tal modo, la prueba parece demasiado ad hominem para tener la validez que se esperaría atribuirle como base de toda metafísica fundada con pulcritud. ¿Y si sencillamente se rechaza este modo supuesto de definir, esto es, de definir por medio del género cualificado por la diferencia específica? ¿O incluso si, aceptando definir mediante género y diferencia, se establecen condiciones especiales para el caso extremo de los géneros superiores, que constituyen la clave de bóveda del edificio lógico, en este caso, el ser y el uno? ¿Se lograría eludir la dificultad que plantea la prueba?

Para Aristóteles, una definición es un enunciado que exhibe, dice o expresa la esencia o quididad de una cosa. En Tópicos I 5 se dice que la

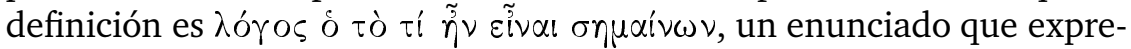
sa la esencia (101b38); en VI 2 es la expresión que exhibe la esencia

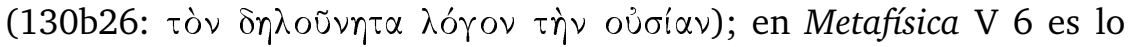

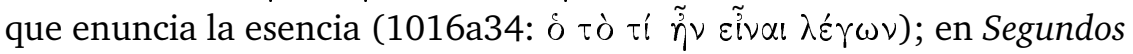

${ }^{8}$ Sobre esto, véase P. Moraux, Der Aristotelismus bei den Griechen III, p. 474. 


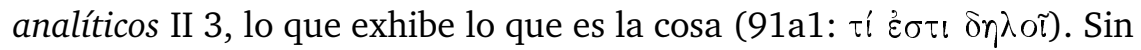
embargo, ¿́por medio de qué la definición enuncia, exhibe o expresa la esencia de algo? Existe una fórmula para que las definiciones realicen la operación de exhibir la esencia, y esta fórmula es precisamente la estructura género + diferencia. Una buena definición se elabora por medio del género y de la diferencia (Top. VI 4 141b25-27). En el libro VI de los Tópicos se examina cómo formular una buena definición, y también se enumeran algunos casos malogrados de definición (en los cuales, precisamente, el estándar de género y diferencia sufrió algún daño). Por lo tanto, no es de sorprender que precisamente aquí encontremos las reglas explícitas que deben seguirse para lograr una buena definición, que será imposible si alguien pretende que el ser sea un género único de todo lo que es. Un útil resumen de esto aparece al final de Tópicos IV, libro dedicado al género:

Dado que ciertas personas opinan que la diferencia también se predica en la esencia de las especies, para distinguir el género de la diferencia debemos servirnos de los elementos ya mencionados: primero, que el género tiene una extensión mayor que la diferencia; después, que cuando se pregunta cuál es la esencia de algo, es más pertinente dar como respuesta el género que la diferencia (quien dice que el hombre es un animal exhibe mejor la esencia del hombre que si dijera que es terrestre); por último, que la diferencia siempre expresa la cualificación de un género, mientras que el género no expresa la de una diferencia: quien dice terrestre dice animal de cierto modo, pero quien dice animal no dice terrestre de cierto modo. (128a20-29)

Estos temas se analizarán más a fondo en el libro VI, pero este pasaje del libro IV resulta valioso para nosotros porque menciona que todo eso es válido para ciertas personas: las que consideran que la diferencia forma parte de la expresión que dice o exhibe la esencia de la cosa (128a20: $о$ $x \varepsilon \tilde{\imath} \tau \iota$ ). Para ellas es necesario distinguir la diferencia de la otra parte del definiens; a saber, el género. ¿Quiénes son esas personas? Todo indica que son precisamente los platónicos y los aristotélicos, quienes adoptan el género más la diferencia, lo cual produce la especie, como fórmula para la expresión que muestra la esencia de algo. Básicamente tendríamos tres reglas: (i) el género es más extenso que la especie, por lo tanto, no se predica de ella; (ii) la diferencia es más extensa que la especie (bípedo se predica de hombre, pero hombre no se predica de bípedo); (iii) el género no se predica de la diferencia, pero se predica de aquello de lo que se predica la diferencia.

Diánoia, vol. LV, no. 65 (Noviembre 2010). 
En Tópicos VI 6 144b4-11, se muestra (ii) que es imposible que la especie se predique de la diferencia, puesto que la diferencia tiene mayor extensión que las especies (144b6). El hombre es un animal terrestre bípedo; no se puede decir, en cambio, que bípedo es hombre, sino sólo que el hombre es bípedo, pues el ser bípedo tiene más extensión que hombre (esto se presenta también, por ejemplo, en los pájaros). El error sería formal, similar a lo que sucede en (i) cuando alguien dice que animal es el hombre y no que el hombre es animal. Ahora bien, la regla (ii) parece plantear una perspectiva diferente de la que Aristóteles adopta, por ejemplo, en la Metafísica, pues allí nos dice que la diferencia última puede servir como definición de la cosa por tener la misma extensión que la especie (es la conclusión a la que llega en $\mathrm{Z}$ 12, y también como la defiende en $\mathrm{H}$ 6), mientras que en los Tópicos Aristóteles subraya que la diferencia es más extensa que la especie. No obstante, hay un modo de conciliar ambas afirmaciones. En la Metafísi$c a$, uno de los problemas consiste precisamente en comprender de qué modo la definición, inevitablemente integrada por partes (pues su fórmula se compone de al menos dos partes, género y diferencia), enuncia algo necesariamente único. Esto lleva a Aristóteles a poner de relieve la diferencia entre la mención de las partes constitutivas de un objeto (como ladrillos, piedras y maderos para una casa), lo cual no constituye tal unidad (a no ser en potencia), y la definición meramente formal de este mismo objeto (como alojamiento para personas y bienes) que, aunque incluye partes en su fórmula, enuncia algo necesariamente único. Aristóteles, en particular en Z 12, vuelve a esa perspectiva y retoma la definición así concebida y la división que conduce a ella (algo similar a lo que sucede en Segundos analíticos II 13, donde la división vuelve a ocupar un sitio central en el procedimiento de la definición, a pesar de las críticas expresadas en otras partes a las dicotomías platónicas). Es en este contexto cuando señala, en $\mathrm{Z} 12$, que la última diferencia, bípedo, puede servir como definición de hombre en la medida en que resume las demás diferencias, suponiendo, desde luego, que las divisiones que llevaron a ella se establecieron correctamente. Así, bípedo recupera terrestre y también todas las demás diferencias que marcan el género animal en el caso de la definición de hombre. Sin embargo, por separado, bípedo no puede designar al hombre (pues los pájaros también son bípedos), ya que es más extenso que la especie, aunque sea coextensivo con ella cuando integra en sí todas las demás divisiones que llevaron a su obtención. De este modo, aunque la diferencia, cuando se considera aparte, sea más extensa que la especie, el género especificado por las diferencias, resumidas en la última de ellas, tiene 
que ser coextensivo con la especie. Aristóteles busca así conciliar ambas posiciones al enfatizar ora la mayor extensión de la diferencia en relación con la especie, cuando se considera aparte, ora su coextensión con la especie, cuando se ve desde la perspectiva de las divisiones que condujeron a su obtención (y que correspondería a la distinción entre bípedo a secas y terrestre bípedo, en el caso de la definición de hombre).

En las líneas inmediatamente anteriores, 144a28-b3, se dice que (i) el género tiene más extensión que la especie —lo que impide que hombre se predique de animal-y también más extensión que la diferencia en una definición formulada correctamente (definir, por ejemplo, hombre como animal sustancial haría parecer que la diferencia es más extensa que el género). Hay un detalle aquí que merece considerarse. La definición estándar para hombre, con la que Aristóteles trabaja la mayoría de las veces, es animal terrestre bípedo. En este caso, el género tiene más extensión que la diferencia. Sin embargo, si la definición fuese, por ejemplo, animal racional, como la racionalidad se aplica también a los dioses, no se seguiría que el género tiene necesariamente mayor extensión que la diferencia, sino sólo que no pueden ser de la misma extensión. Señalar que el género es más extenso parece ser un compromiso que Aristóteles acepta en función de concebir la definición íntimamente bajo la forma de una (correcta) división. Si fuera propenso a establecer sus definiciones al margen de los estándares de división, no tendría por qué señalar este último punto.

Sin embargo, lo que me interesa señalar es que, inmediatamente después de estas observaciones, Aristóteles agrega que el género tampoco se predica de la diferencia, pues, dice, se admite que (iii) el género se predica de aquello de lo cual se predica la diferencia, sin que por ello se predique directamente de la propia diferencia. El ejemplo que Aristóteles ofrece es: animal se predica de hombre, ganado, etc., pero no de la propia diferencia que se dice de la especie (144a35-36: oن $x \alpha \tau^{\prime}$

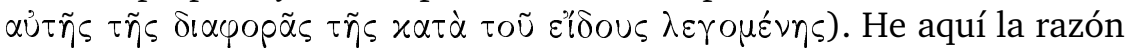
que aduce para tal restricción:

Por lo tanto, si animal se predicase de cada una de las diferencias, diversos animales $(\pi \circ \lambda \lambda \dot{\alpha} \zeta \tilde{\varphi} \alpha)$ se predicarían de la especie, pues las diferencias se predican de la especie. (144a36-b1)

Aparentemente, el argumento es el siguiente. Una vez definido hombre como animal terrestre bípedo, al ser las diferencias mismas un animal cada una, el hombre sería entonces varios animales; a saber, tantos

Diánoia, vol. LV, no. 65 (Noviembre 2010). 
animales cuantas diferencias hubiera. Tendríamos como resultado algo así: que algo sería animal animal animal $_{3}$ si fuera animal terrestre bípedo. Esto sería como una versión exacerbada del psitacismo. En efecto, parece que la idea es: si bípedo es bípedo animal, y terrestre es terrestre animal, obtendríamos algo parecido a animal terrestre (animal) bípedo (animal), en caso de que se introdujera animal cada vez que se agregase una diferencia: animal (terrestre) animal (bípedo) animal, lo cual generaría un psitacismo exacerbado si el género se predicara de la diferencia: animal animal animal. Aunque sólo se tome como definición de hombre la última diferencia, bípedo, el resultado sería que es un bípedo animal; por lo tanto, que es bípedo animal animal, pues bípedo es un animal, lo que genera una repetición de animal. ${ }^{9}$ Si traspusiéramos este resultado al problema inicial, obtendríamos algo como lo siguiente. $X$ se definiría como ser de tal-y-tal tipo. Sin embargo, de tal-y-tal tipo también es, y es necesariamente; se seguiría de ahí que $X$ es un ser de tal-y-tal tipo (ser), lo que nos lleva directamente a ser presas del psitacismo: ser (de tal-y-tal tipo) ser, y así sucesivamente.

Esto constituiría la faceta formal del problema, si bien hay otra faceta relacionada con el contenido, por decirlo así. Hasta ahora he enfatizado cómo la séptima aporía, donde encontramos el argumento en cuestión, está estrechamente ligada a la aporía anterior, la sexta. No obstante, cabe destacar también que ambas guardan relación con la aporía 11 , que se presenta, aunque no exclusivamente, como la más difícil y la más necesaria en lo que respecta al conocimiento de la verdad (B 4 1001a45). ${ }^{10}$ Ahora bien, esta última aporía entraña el siguiente problema: si el ser y el uno no son principios, entonces, aparentemente, ningún universal puede ser principio (cfr. 1001a19-20, cuya terminología está en estricta consonancia con el problema del universal en Z 13), lo cual parece tener como consecuencia que los particulares serán principios, ya que nada más, excepto los universales, parece poder funcionar como tal. Sin embargo, de ser así, volvemos a la aporía 8, que también se presenta como la más difícil de todas y la que más urge examinar (B 4 999a24-26): si sólo pueden ser particulares, ¿cómo se pueden conocer los principios? Obviamente estas cuatro aporías se entretejen en torno a una misma dificultad, la cual se presenta, en sus dos facetas, como la más compleja y la que urge resolver para conocer la verdad: si el

${ }^{9}$ Sobre el fenómeno del psitacismo y su erosión devastadora para las definiciones, véase en especial Alfonso Correa Motta, "A Língua dos Papagaios, a Diferença e o Ser".

${ }^{10}$ Sobre las aporías, véanse en especial Enrico Berti, "Aporiai 6-7", y Walter Cavini, "Aporia 11". 
principio fuera universal, ¿cómo evitar que el ser y el uno sean principios de todo?; si el ser y el uno no son principios, ¿cómo no caer en la afirmación de que los principios son particulares y, por lo tanto, infinitos e incognoscibles?

No sólo es un problema teórico, sino que también se presenta en un plano histórico. Por un lado están los platónicos (y, como continúa la aporía 11, los pitagóricos, para quienes el uno conduce a una teoría metafísica del número); por el otro, los fisiólogos, para quienes algún elemento figura como causa de todo lo que es. Ese elemento (o elementos, en caso de que admitan una pluralidad) es lo que constituye cada cosa y será universal solamente por analogía: este fuego genera esto, ese fuego genera eso, aquel fuego genera aquello; el fuego, por analogía, genera todo lo que es. Así pues, el problema puede presentarse de modo histórico: Aristóteles se encuentra en una encrucijada; ve a los defensores de uno y otro camino, pero no alcanza a ver la salida. Tal vez incluso tengamos un documento donde se sorprende a Aristóteles en plena encrucijada. En efecto, la doctrina de la sustancia sensible que se presenta en la primera parte del libro $\Lambda$, la que va de $\Lambda 2$ a $\Lambda$, justamente muestra un Aristóteles atrapado por los particulares como las causas mismas de todo lo que es (Peleo es el padre de Aquiles, pero mi padre es otro, aunque ambos desempeñen la misma función de principio motor; esto es, de padre) y en busca, no obstante, de una ciencia que exige elevarse de los particulares a algún dominio de lo universal —aunque el precio de ello sea a la simple relación por analogía—. Todo eso muestra la posición decisiva que ocupa Z 13 en la constitución de la metafísica aristotélica madura de los libros centrales de la Metafísica: si la solución que Aristóteles encuentra allí para la forma permite que escape de la universalidad extrema del ser, sin que se difunda entre los particulares, la metafísica aristotélica tendrá un lugar propio para edificarse; de otro modo, quedará deshecha entre los tentáculos de estas aporías.

\section{III}

Pero volvamos a la prueba de III 3 998b22-28. Puede ser instructiva una comparación con la famosa refutación del principio de no contradicción. Este argumento sigue siendo motivo de gran controversia, ${ }^{11}$

${ }^{11}$ Sobre este tema, véase en especial W. Cavini, "Principia contradictionis. Sui principi aristotelici della contradizione"; véanse también los ensayos que acompañan a la nueva edición de la traducción del libro $\Gamma$ en Aristote - Métaphysique Gamma - édition, traduction, études.

Diánoia, vol. LV, no. 65 (Noviembre 2010). 
pero podemos ceñirnos a ciertos puntos sobre los que hay consenso. Una de las dificultades consiste en localizar la prueba exactamente. A mi parecer, se encuentra en IV 4 1006b28-34, lo cual no necesito defender en este análisis. Dondequiera que esté, el hecho es que la prueba deberá presentar las siguientes características. En primer lugar, no se trata de una prueba directa, sino de una refutación de quienes niegan el principio de no contradicción. Aristóteles es bastante enfático a este respecto. Es preciso que quien lo niega diga algo, esto es, que se enfrasque en un discurso sobre el mundo, que quiera decir algo del mundo. En términos de Aristóteles, debe decir algo (1006a19-20: $\lambda \dot{\varepsilon} \gamma \varepsilon I \nu ~ \tau l)$. Hay aquí una exigencia mínima de compromiso, pues el adversario no puede enunciar simplemente una preposición —de, por ejemplo- ni expresar un mero deseo - ojalá - , sino que debe decir algo con lo cual emita un comentario sobre el mundo. No se le debe exigir que diga una proposición, que " $X$ es $Y$ ", pues es justo lo que está en discusión: él afirma que $X$ también es no- $Y$. Sólo hace falta que diga $X$ o diga $Y$; al hacer eso - y el ejemplo ofrecido es que diga: hombre-, el adversario se verá enredado en las reglas de la significación, que exigen un tipo de demarcación del mundo que se cancelaría al negarse el principio de no contradicción. Así, o dice algo - y acepta entonces reglas de determinación del significado-, o sencillamente no dice nada y guarda silencio como las plantas.

Tenga o no éxito con su prueba, el hecho es que Aristóteles pretende establecerla en forma de una refutación: el adversario, para decir algo con significado, necesita admitir el principio que pretende negar. En el caso de nuestra prueba, hay una analogía evidente. El platónico, al postular que el ser es un género, tendrá que lidiar con tesis incompatibles: por un lado, la diferencia necesariamente es y, por consiguiente, participa del ser, o sea, el género se predica de la diferencia; por otro lado, el género no puede predicarse de la diferencia y, por consiguiente, ésta no puede ser. De este modo, el platónico se encuentra en una situación similar a la de quien niega el principio de no contradicción: mientras éste lo supone para poder decir algo con significado, aunque pretenda negarlo, aquél quiere afirmar el ser como género, pero necesita entonces negarlo respecto de las diferencias, lo cual obviamente no puede hacer. Tendrá que dar marcha atrás y corregir su premisa inicial, de que el ser es un género supremo. El argumento funciona, pues, como una impugnación: no demuestra que el ser se difunde en sus diferentes categorías (que es la tesis metafísica aristotélica), pero muestra que el platónico presenta un argumento incoherente con respecto al ser como género supremo.

Diánoia, vol. LV, no. 65 (Noviembre 2010). 
La analogía, sin embargo, termina aquí. En el caso del principio de no contradicción, la prueba de refutación necesita depurarse lo más posible. No se puede presuponer ningún rasgo de esencialismo en ella; si se detecta alguna presuposición de esta naturaleza, entonces la prueba no funciona. No se puede exigir que alguien que niegue el principio de no contradicción presuponga algún rasgo de esencialismo; además, es perfectamente posible aceptar el principio de no contradicción y no casarse con el esencialismo. Aquí, por el contrario, la prueba funciona porque hay tesis bien determinadas — que aceptan los platónicossobre cómo se deben obtener las definiciones y que resultan incompatibles con la tesis del ser como género supremo. Al parecer, estas reglas se consideran tan fijas que en ningún momento se duda en concluir el rechazo del presupuesto contrario, es decir, que el ser es el género supremo. En la prueba del principio de no contradicción, por tratarse del principio considerado el más básico de todos, estaba en discusión no un problema escolar, sino un problema general sobre la posibilidad misma de conocer algo. Quien pretende conocer algo, lo que sea, debe presuponer ese principio como regla para obtener un conocimiento. Eso le da una dimensión que va más allá de una u otra escuela, sino que es válida para todas ellas. Aristóteles es bastante explícito sobre esta dimensión del principio. No sólo es válida, por cierto, para todo discurso entre personas; también es necesaria para que cada uno pueda pensar, en su discurso interior. Ahora bien, en contraste, la prueba de que el ser no es un género es en definitiva algo muy íntimo de una escuela, de un modo muy preciso de concebir las definiciones. Para rebatirla puede esgrimirse una serie de objeciones a todas las presuposiciones que fundamentan esta posición tan peculiar en lo relativo a la naturaleza de la definición y su fórmula. Así, se trata prácticamente de una prueba con dedicatoria: ad platonicos.

Esto no quiere decir que la prueba carezca de algún significado particularmente importante a los ojos de Aristóteles. Como vimos, se encuentra en medio de una red de aporías que, precisamente, Aristóteles considera las más difíciles y las más decisivas para el conocimiento de la verdad: ¿son universales los principios y qué tipo de universalidad debe atribuírseles, o bien debemos encaminarnos a una metafísica sólida de lo concreto, aceptando solamente por analogía funciones comunes desempeñadas por particulares? Aristóteles se inclina por los universales, pero no está dispuesto a aceptar la máxima universalidad para el principio. El argumento que formula, intrínseco a la escuela platónica, sirve justamente para obstaculizar, en el campo de los universales, la tesis de que el ser es un género supremo, junto con el uno.

Diánoia, vol. LV, no. 65 (Noviembre 2010). 
No obstante, la prueba no deja de ser negativa. De esto no es posible deducir la tesis metafísica aristotélica de la difusión categorial del ser; más todavía, ni siquiera se vislumbra a qué solución llegará Aristóteles para el tipo de universalidad que atribuirá a sus formas, en vista de que ha negado a ese principio la estructura universal más fuerte, la de máxima extensión del ser y del uno. Esto permite comprender el sentimiento de insatisfacción con que se recibió la prueba. Sumamente precisa, dependiente de una serie de presuposiciones que pocas escuelas estarían dispuestas a admitir, la prueba es casi un ajuste interno de cuentas de Aristóteles, cuyo objeto es impedir que el platonismo derive hacia la máxima generalidad y a la consecuente matematización de la metafísica bajo la figura del uno como principio.

\section{IV}

Así pues, la prueba sirve para hacer inviable la perspectiva platónica, sin describir todavía el rumbo exacto del argumento aristotélico sobre la naturaleza del ser. Las presuposiciones sobre la fórmula de la definición y su estructura son aceptadas por platónicos y aristotélicos, pero bastaría que fuesen aceptadas por los primeros para que la prueba funcionara. Ésta tiene típicamente la naturaleza refutativa y, en sus límites, pretende exhibir una incoherencia en el argumento platónico, lo cual puede generarse con tesis únicamente platónicas.

Para concluir, me referiré a otra prueba que, conectada con ésta, es aún más precisa y funciona con premisas exclusivamente platónicas. Aristóteles inicia el último libro de la Metafísica, el libro XIV, con una crítica a la manera en que los platónicos conciben los contrarios como principios. Esta crítica tiene dos vertientes. La primera, más general, se refiere al hecho de que se tomen directamente los contrarios como principios sin suponer un tercer elemento, el sustrato, que se mantiene durante la transición de un contrario al otro. Ese tema se desarrolló en particular en el primer libro de la Física, sobre todo en relación con los fisiólogos, pero aquí se aplica a la perspectiva platónica, que también pretende operar con base en dos contrarios exclusivamente. La segunda crítica se refiere a cómo proceden: puesto que al haber ignorado el tercer elemento o sustrato se limitan a los dos contrarios, no pueden sino hacer que uno de los contrarios funcione como el elemento material o sustrato. Lo anterior es una consecuencia inevitable del primer error, pero aquí se analiza aparte: cómo uno de los contrarios asume la función de materia o sustrato. Por lo tanto, esto nos remite de nuevo a las doctrinas no escritas de Platón, y el texto de Aristóte- 
les da a entender que había importantes controversias sobre el modo en que estas doctrinas concebían uno de los contrarios como materia. Algunos platónicos suponían que era lo desigual, al cual le atribuían una naturaleza múltiple; otros adoptaban la multiplicidad misma como el elemento material. Lo desigual era visto desde la perspectiva de lo grande y de lo pequeño, pero otros pensaban que sería mejor adoptar lo mucho y lo poco, pues estos últimos serían más afines a principios de números, mientras que los primeros caracterizarían más las magnitudes. Otros más preferían el exceso y la carencia, considerando que son los términos más generales para englobar lo grande y lo pequeño, por un lado, y lo mucho y lo poco, por el otro.

Las doctrinas y discusiones internas del platonismo son poco claras para nosotros; además, hay problemas textuales y de interpretación que dificultan particularmente la tarea del intérprete. Aun así, lo que parece delinearse es que, frente a todas estas controversias intrínsecas al platonismo, Aristóteles piensa que quienes oponen el uno a la multiplicidad, tomando esta última como el elemento material, son los que hablan con mayor verosimilitud, aun cuando no considere que sean lo suficientemente claros (1087b30-31). Por fortuna no necesito entrar en los detalles de estas discusiones, pues sólo quiero referirme a un argumento que Aristóteles presenta contra quienes, a su parecer, se distancian mucho de lo verosímil al sostener que lo desigual es algo único, mientras que la díada indefinida estaría compuesta de lo grande y lo pequeño. Aristóteles hace dos observaciones en relación con estos pensadores platónicos. En primer lugar, alega que grande y pequeño, así como poco y mucho, parecen ser accidentes antes que sustratos, cuando justamente deberían estar funcionando como sustratos. En segundo lugar, observa que:

Más allá de este error, lo grande y lo pequeño, así como todas estas determinaciones similares, son necesariamente relativos; ahora bien, lo relativo es, de todas las categorías, la de menor naturaleza o sustancia; es incluso posterior a la cualidad y a la cantidad; de hecho, lo relativo es, como se dijo, una afección de la cantidad, y no materia. (XIV 1 1088a21-25)

La idea es clara: lo grande y lo pequeño deberían funcionar como principios a título de materia, pero difícilmente podrán realizar tal tarea, pues, entre las categorías, lo relativo es lo que menos sustancia o naturaleza tiene. "Como se dijo" se refiere a las líneas inmediatamente anteriores, en las cuales se dice que lo grande y lo pequeño son afecciones antes que sustratos. Todo el problema radica en saber de dónde viene la

Diánoia, vol. LV, no. 65 (Noviembre 2010). 
premisa de que lo relativo es, entre las categorías, la que menos realidad tiene. ¿Es exclusivamente platónica, o también es aristotélica, o es propiamente aristotélica? A este respecto, Ross anota lo siguiente en su comentario: "la descripción de la relación como la menos sustancial de las categorías es única en Aristóteles". ${ }^{12}$ Tiene razón, pues no hay otro pasaje que proceda de modo similar, a no ser aquel al que remite y se encuentra en Ética nicomáquea I 4. En efecto, en ese capítulo, dedicado a la crítica de la noción platónica del bien, Aristóteles inicia su crítica refiriéndose a un argumento cuya primera premisa, por lo menos, es sin duda platónica:

Quienes introdujeron esta opinión [i.e. la de la Idea del Bien] no postulaban ideas en los elementos que declaraban como anterior y posterior; por esta razón tampoco establecían una idea de los números. Ahora bien, lo bueno se dice en lo que es, en la cualidad y en lo relativo; lo que es en sí y la sustancia son anteriores por naturaleza a lo relativo (éste se asemeja, pues, a una ramificación y accidente del ser), de modo que no hay una idea común a estos elementos. (1096a17-23)

Existen ciertamente la Díada, la Tríada y así sucesivamente, pero no una Idea única de todos los Números, pues están en una relación de anterioridad y posterioridad; ésta es una posición platónica. Un poco más adelante, en 1096b16, Aristóteles se refiere a una división platónica de los bienes entre aquellos que lo son en sí mismos y aquellos que lo son como medios para otros bienes; estos últimos son relativos en la medida en que un medio ha de considerarse bueno (y perseguirse como un bien) porque es relativo a un fin que es bueno. Los bienes en sí mismos satisfacen tanto la descripción " $X$ es un buen $Y$ ", situación donde bueno aparece en la categoría de la cualidad, o simplemente " $X$ es un (o lo) bueno", y aquí bueno parece ocupar la posición de la categoría de la sustancia, en posición predicativa absoluta. Así pues, con apego a los textos platónicos, lo bueno se dice según estas tres categorías. Falta saber si la última premisa, la de la anterioridad por naturaleza de la sustancia con respecto a lo relativo, es platónica, aristotélica o común a ambas posiciones (y eventual o probablemente a terceros). Sin duda, es necesariamente platónica, pero no necesariamente exclusiva de los platónicos. Por el contrario, la posición más verosímil es que se trata de una tesis común, probablemente aceptada de forma muy amplia: por naturaleza, para que algo sea relativo a algo, primero deben existir estos dos elementos a fin de establecer una relación entre ellos. El

${ }^{12}$ Aristóteles, Aristotle's Metaphysics, ed. D. Ross, vol. II, p. 473. 
argumento, en $E N$ I 4, funciona así con premisas platónicas y con una premisa común, a la que deben asentir también los platónicos.

Esto podría predisponernos a aceptar que la tesis de que lo relativo es la naturaleza o sustancia mínima sea también una tesis común o por lo menos aceptada por platónicos y aristotélicos. No obstante, convendría ser más cautelosos en este sentido, pues la tesis en cuestión es una versión bastante más específica de la anterioridad de la sustancia con respecto a lo relativo. En efecto, es compatible con esta última que la cualidad sea posterior a la sustancia (para ser de algún tipo, primero necesita ser), o que la cantidad sea posterior a la categoría de la sustancia, sin que haya necesidad de establecer un orden entre las diferentes categorías, en el que lo relativo ocuparía el último lugar, en este caso, como una afección de la cantidad. La sustancia puede quedar en una posición de anterioridad, central con respecto a las otras categorías, que no entrarían en jerarquización alguna sino sólo en relación con la sustancia (que funciona, entonces, como ser primero). Ésta es, por cierto, la posición que guarda una armonía más natural con la tesis metafísica aristotélica del ser que hallamos en los libros centrales de la Metafísica. Además, un detalle del pasaje de XIV 1 parece indicar que se trata de una tesis platónica. En efecto, el "como se dijo" se refiere a algunas líneas anteriores, cuando Aristóteles dice que lo grande y lo pequeño, así como lo poco y lo mucho, parecen ser más bien afecciones de las magnitudes y de los números, respectivamente (1088a17-19). Por esta razón, dado que el número y la magnitud son cantidades, y dado que grande y pequeño o mucho y poco son relativos, éstos parecen ser más

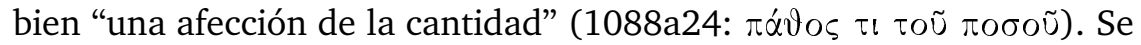
trata, pues, de una consecuencia que los platónicos deben admitir en el interior de su teoría, aun cuando se presente con una terminología que no es exclusivamente platónica, sino, por el contrario, común y aceptada por muchos (el lenguaje de las categorías): lo relativo es lo que menos realidad o sustancia tiene, puesto que se le ha relegado, según los platónicos, a la última posición, como mera afección de alguna otra categoría. Así, la tesis mencionada en este pasaje del último libro de la Metafísica, a diferencia del de EN I 4, parece circunscribirse a los platónicos -y Aristóteles mostraría una incoherencia más en las tesis de quienes defienden que los contrarios son principios según esta lectura matemática de lo grande y lo pequeño como sustrato o materia-.

Recientemente, Christopher Shields presentó un examen extremadamente minucioso de la noción de homonimia en Aristóteles. ${ }^{13} \mathrm{Su}$ libro

${ }^{13}$ C. Shields, Order in Multiplicity: Homonymy in the Philosophy of Aristotle. Más

Diánoia, vol. LV, no. 65 (Noviembre 2010). 
es profuso en detalles; en particular, Shields reinterpretó la noción de significación focal como una homonimia de dependencia respecto de un núcleo de significado fundada en una relación causal entre el caso central y el resto. No entraré en los detalles de esta reinterpretación, me basta con señalar que, para Shields, a pesar de la noción aristotélica de la homonimia, de suma riqueza y sutilmente analizada, lo que queda es que dos términos, el ser y el bien, no se ajustan a las condiciones de homonimia. Dejemos a un lado el problema de la homonimia o sinonimia del bien y concentrémonos en el problema del ser. En opinión de Shields, dada la compleja doctrina aristotélica de la homonimia, para mostrar que el ser es un homónimo según la significación focal (o, en su terminología, un homónimo de dependencia respecto de un núcleo de significado), se debe establecer, en este orden, primero que (i) no es sinónimo, para entonces mostrar que (ii) hay una asociación entre sus sentidos y, por último, mostrar que (iii) esta asociación se da en virtud de una dependencia respecto de un núcleo de significado. Ahora bien, para él, la prueba fracasa desde (i), pues no consigue mostrar que el ser no es unívoco. Podemos resumir así el argumento de Shields para la sinonimia del ser:

(1) dos $F$ son $F$ no-sinónimamente sólo si son inconmensurablemente $F$.

Shields recurre a Física VII 4 como base textual para ilustrar lo anterior. En esa obra, a fin de mostrar que los cuatro sentidos del cambio (la generación, la alteración, el crecimiento y el desplazamiento en el espacio) no son conmensurables entre sí, lo cual conduce a considerarlos como homónimos, Aristóteles echa mano de un principio suyo, según el cual todo aquello que no es sinónimo es inconmensurable (248b6-7:

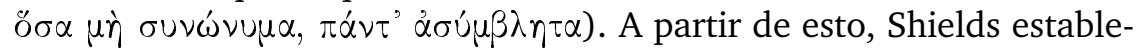
ce que:

(2) los seres ( $\tau \grave{\alpha}$ ő $\nu \tau \alpha)$ son siempre conmensurables entre sí.

Para la tesis (2), Shields invoca precisamente Metafísica XIV 1 1088a2225 , el pasaje que acabamos de examinar, y sugiere, con base en ese pasaje, que "Aristóteles parece afirmar directamente que el ser puede admitir grados". ${ }^{14}$

recientemente, Julie Ward publicó una relectura de este libro: Aristotle on Homonymy (Dialectic and Science), Cambridge, 2008, en la que intenta reinsertar en la doctrina de la homonimia las nociones de ser y bien, que Shields, como veremos, dejó fuera del campo de la homonimia.

${ }^{14}$ C. Shields, op. cit., p. 264.

Diánoia, vol. LV, no. 65 (Noviembre 2010). 
De donde:

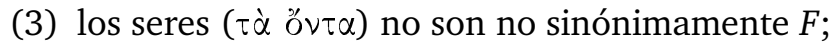

(4) la distinción entre homonimia y sinonimia es exhaustiva;

(5) los seres ( $\tau \grave{\alpha}$ ő $\tau \tau \alpha)$ son siempre sinónimamente referidos;

(6) si los seres ( $\tau \grave{\alpha}$ ő $\nu \tau \alpha)$ son siempre referidos de modo sinónimo, son unívocos;

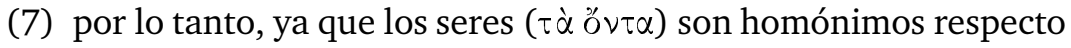
de un núcleo de significado sólo si son no unívocos o no sinónimos, los seres ( $\tau \dot{\alpha}$ ŏv $\tau \alpha$ ) no son homónimos de dependencia respecto de un núcleo de significado - sencillamente porque no son homónimos, sino sinónimos o unívocos-.

El argumento de Shields coincide con la corriente contemporánea de tomar el ser de la predicación como típicamente unívoco; puede distinguirse de manera lógica el es de la existencia y de la identidad del es de la predicación, pero este último es, internamente, unívoco. Ésta no era, sin embargo, la perspectiva de Aristóteles, para quien el es de la predicación se refleja en las diferentes categorías o géneros supremos del ser. Pero ¿cómo evitar el argumento de Shields? La salida estribaría en que puede leerse (2) restringiéndola a la escuela platónica, sin afectar al aristotelismo, como propuso Shields. No obstante, hay a primera vista una dificultad considerable para esta empresa, pues más adelante, en 1088a29-35, Aristóteles presenta un argumento con la finalidad específica de mostrar que lo relativo es mínimamente sustancia

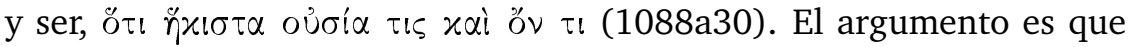
sólo lo relativo no posee un tipo de transformación concomitante: la sustancia está ligada a la génesis y corrupción simples; la cualidad, a la alteración; la cantidad, al aumento y disminución; el lugar, al desplazamiento. Esto serviría de indicio de que lo relativo ocupa una posición inferior con respecto a las otras categorías, lo cual resulta algo extraño, pues limitaría el problema a una lista de sólo cinco categorías, cuando Aristóteles parece dispuesto a aceptar más de cinco. A continuación, éste observa que algo puede sufrir un cambio en la relación sin haber sufrido ninguna modificación en sí mismo. Tal es el caso de lo que se ha convenido en llamar "cambio de Cambridge": $A$ es más alto que $B$, pero se vuelve más bajo que $B$ sencillamente porque $B$ pasó por un aumento cuantitativo sin que $A$ sufriera cambio alguno. De este modo, $A$ dejó de ser más alto y pasó a ser más bajo que $B$. Ahora bien, 
no hay ninguna razón para que Aristóteles no acepte la observación sobre el cambio de Cambridge en su propia reflexión, lo que nos llevaría a pensar que también acepta que lo relativo tiene ser en grado mínimo.

Cabe señalar que en dos traducciones francesas el problema aparece

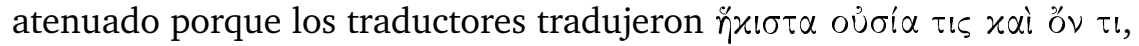
en 1088a30, como si afirmase que lo relativo "no es en absoluto una sustancia ni un ser real"15 o "no es de modo alguno una sustancia ni un ser", ${ }^{16}$ mientras que, en 1088a23, la expresión equivalente $\ddot{\eta} \varkappa 1 \sigma \tau \alpha$

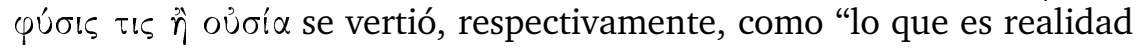
determinada o sustancia en el menor de los grados" y "lo que es naturaleza o sustancia en el menor de los grados". * Sin embargo, a lo largo de estas siete líneas, $\ddot{\eta} \varkappa$ $\sigma \tau \alpha$ debe entenderse —en ambos pasajes- como lo que es en grado mínimo sustancia o ser, y no que no es de modo alguno sustancia o ser. Está claro que el hecho de que lo relativo no sea de modo alguno sustancia no daña la tesis de la homonimia del ser: por el contrario, es exactamente eso lo que esperamos que Aristóteles diga. Pero si éste adoptara la tesis de la conmensurabilidad de los seres, entonces habría un problema, y grande: si fueran todos conmensurables (estando lo relativo en la posición inferior de la escala de ser; la sustancia, en la posición superior, y las otras categorías, en posiciones intermedias), no serían homónimos. Ciertamente son conmensurables desde la perspectiva platónica; pero ¿lo serían también en la voz de Aristóteles? Si lo fueran, Shields tendría toda la razón en decir que, a pesar de la riqueza del análisis aristotélico de la homonimia, dos nociones —el ser y el bien- escapan a ella, pues serían conmensurables y unívocas (aun cuando Aristóteles se haya comprometido con esta sofisticada doctrina de la homonimia justo para mostrar que el ser y el bien no son sinónimos).

Según el pasaje XIV 1 de la Metafísica, lo relativo estaría en la zona inferior de una escala (conmensurable) de ser, cuyo punto culminante estaría ocupado por la sustancia, porque lo relativo es un atributo de la cantidad. Sin embargo, es una tesis de Aristóteles, precisamen-

${ }^{15}$ Aristóteles, La Métaphysique, ed. J. Tricot, vol. II.

${ }^{16}$ Aristóteles, Aristote: Métaphysique, ed. M.-P. Duminil y A. Jaulin.

*Ambas expresiones, en francés en el original portugués: "celle qui est le moins réalité déterminée ou substance" y "ce qui est le moins une nature ou une substance" para 1088a23, respectivamente; y "n'est nullement une substance, ni un être réel" y "n'est pas du tout une substance ni un être" para 1088a30, respectivamente. [N. del t.] 
te, que los géneros supremos o categorías son irreductibles unos a los otros:

Se dice que son distintos en cuanto al género los elementos cuyo sustrato primero es distinto y que no se reducen uno al otro, ni ambos a un tercero, como la forma y la materia son distintos en cuanto al género, así como todo lo que se dice según una figura distinta de la predicación del ser (pues unos designan la sustancia de los seres; otros, una cualidad; otros más, conforme a las divisiones previamente establecidas); tampoco estos últimos se reducen unos a los otros o a un tercero. (Metaf. V 28 1024b9-16) ${ }^{17}$

Ahora bien, Aristóteles afirma que lo relativo es ínfimamente sustancia porque es un atributo de la cantidad; y es un atributo de la cantidad porque se toma como grande y pequeño (o mucho y poco), y esto es un atributo de la cantidad. De tal suerte, la tesis parece ser que la doctrina de las categorías, cuando se aplica a las tesis ontológicas de los principios platónicos, arroja como resultado una línea conmensurable para el ser, ocupada en la parte superior por la sustancia, y en la inferior, por lo relativo. Esto realza en particular lo inverosímil de esta tesis platónica (que toma lo grande y lo pequeño como principios a título de sustrato), ya que lo relativo - lo que menos ser tiene- debería entonces ser principio de la sustancia - lo que más ser tiene-, puesto que lo grande y lo pequeño, que son relativos, son principios de todo lo que es. Pero precisamente esto es absurdo: que lo que es ser en grado mínimo sea principio de lo que es ser en grado máximo.

No obstante, cuando habla en su propio nombre, Aristóteles no está interesado en establecer una línea conmensurable de todo lo que es, sino que simplemente coloca la sustancia en una posición principal, anterior a todas las demás categorías, sin distribuirlas en una misma escala de ser. Cuando se refiere al cambio ( $\mu \varepsilon \tau \alpha \beta o \lambda \eta \dot{)}$ ), dice que éste ocurre en cuatro categorías: según la sustancia (generación y corrupción), según la cualidad (alteración), según la cantidad (aumento y disminución) y según el espacio (desplazamiento). Sin embargo, sólo los tres

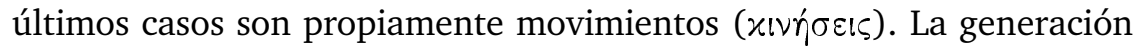
y corrupción son una alteración y, por consiguiente, se apegan al estándar común de los tres elementos del cambio - lo que permanece (el

${ }^{17}$ Lo cual no implica que no haya, en particular en el tratado de las Categorías, cierta vacilación e indeterminación con respecto a la categoría a la que pertenecen ciertos elementos. Acerca de esto, véase en particular F. Brentano, On the Several Senses of Being in Aristotle, en especial las pp. 146-148.

Diánoia, vol. LV, no. 65 (Noviembre 2010). 
sustrato), de dónde cambia y para dónde, procediendo de un contrario al otro-, pero no mantienen el mismo sustrato a lo largo del cambio, a diferencia de todo lo demás que está sujeto al movimiento, durante el cual se conserva un mismo sustrato. Aristóteles dice lo siguiente a este respecto:

En cuanto a la sustancia, no hay movimiento (xínoเs) porque no hay, entre los seres, un contrario de la sustancia. Tampoco hay movimiento en cuanto a la relación, pues puede suceder que, cuando un relati-

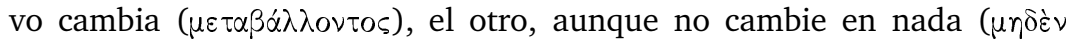

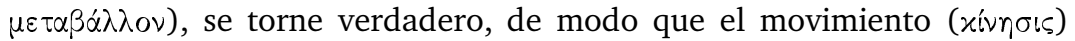
de ambos es accidental. Tampoco hay movimiento en cuanto al agente y paciente o de lo que es movido y lo que mueve, porque no puede haber mo-

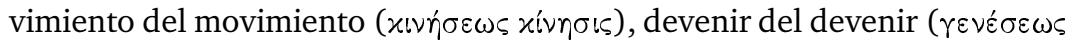
$\left.\gamma^{\varepsilon} v \varepsilon \sigma เ \varsigma\right)$ o, en general, cambio del cambio ( $\left.\mu \varepsilon \tau \alpha \beta o \lambda \tilde{n} \varsigma \mu \varepsilon \tau \alpha \beta o \lambda \dot{\eta}\right)$. (Física $\mathrm{V}$ 2 225b10-16)

Aristóteles habla aquí en su propio nombre. Vuelve a mencionar el fenómeno del cambio de Cambridge: Pablo pasa a ser más bajo que Juan, aunque Pablo no haya sufrido ningún cambio, pero al crecer Juan ahora se tornó verdadero que Pablo es más bajo que Juan, lo cual antes era falso. Esto es propio de lo relativo, aunque otras categorías tienen también sus atributos propios - la de agente y paciente, por ejemplo, no sufre movimiento, como tampoco la sustancia en sentido estricto-. Hay rasgos que se aplican a una categoría, pero no a otra; esto no las descalifica para colocarlas al final de la lista como aquello de sustancia en grado mínimo, sino sólo las cualifica de diferente manera, y es precisamente esta cualificación diferente lo que constituye, para Aristóteles, la difusión del ser en sus géneros supremos, sin que se ordenen en una sola línea jerarquizada y conmensurable de ser.

\section{V}

A manera de conclusión bastante resumida: la prueba de que el ser no es un género sigue el estándar que Aristóteles puede admitir para las pruebas relativas a los principios que establecen los dominios de las disciplinas. Dicha prueba es refutativa; bloquea una posición adoptada históricamente -en este caso, la posición de los platónicos, que postulan como principios lo que más extensamente es-. Si bien impedir un error no equivale a descubrir la verdad, contribuye a ello. Desde la perspectiva de Aristóteles, no hay prueba alguna de los principios. Éstos

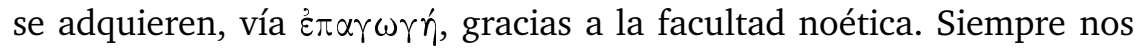


sentimos frustrados con las pruebas meramente refutativas que Aristóteles presenta - del principio de no contradicción, de que el ser no es un género-. No obstante, para Aristóteles, nuestra frustración proviene de una ilusión: la de encontrar pruebas para los primeros principios. Si renunciáramos a esta ilusión, entonces podríamos apreciar mejor el arte aristotélico de poner obstáculos al error.

[Traducción de José Alberto Barrañón Cedillo]

\section{BIBLIOGRAFÍA}

Alejandro de Afrodisias, Commentaria in Aristotelem Graeca, vol. I, In Aristotelis Metaphysica Commentaria, ed. M. Hayduck, G. Reimeri, Berlín, 1891.

Amonio, Commentaria in Aristotelem Graeca, vol. IV, parte 4, In Aristotelis Categorias Commentarius, ed. A. Busse, Berlín, G. Reimeri, 1895.

Aristóteles, Aristote: Métaphysique, trad. M.-P. Duminil y A. Jaulin, Garnier Flammarion, 2008.

—- Aristote: Métaphysique Gamma, trad., ed. y estudios de A. Stevens y M. Hecquet-Devienne, Éditions Peeters, Louvain-la-Neuve, 2008.

— Aristotle: Posterior Analytics, 2a. ed., ed. Jonathan Barnes, Oxford University Press, Oxford, 1994.

— Aristotle's Metaphysics, revisión del texto, introd. y comentario de W.D. Ross, Clarendon, Oxford, 1924, 2. vols.

— L La Métaphysique, trad. y notas de J. Tricot, Vrin, París, 1986, 2 vols.

Berti, E., "Aporiai 6-7", en Crubellier y Laks, Aristotle's Metaphysics Beta, pp. 105-133.

Bonitz, H., Commentarius in Aristotelis Metaphysicam, Georg Olms, Hildesheim/Nueva York, 1992.

Brentano, F., On the Several Senses of Being in Aristotle, trad. R. George, University of California Press, Berkeley, 1975.

Cavini, W., "Aporia 11", en M. Crubellier y A. Laks, Aristotle's Metaphysics Beta, pp. 175-188.

_- "Principia contradictionis. Sui principi aristotelici della contradizione", Antiquorum Philosophia, vol. 1, 2007, pp. 123-169, y vol. 3, 2009, pp. 159187.

Correa Motta, Alfonso, "A Língua dos Papagaios, a Diferença e o Ser", Cadernos de História e Filosofia da Ciência, vol. 13, no. 2, 2003, pp. 205-231.

Crubellier, M. y A. Laks, Aristotle's Metaphysics Beta, Oxford University Press, Oxford, 2009.

Dexipo, Commentaria in Aristotelem Graeca, vol. IV, parte 2, In Aristotelis Categorias Commentarium, ed. A. Busse, G. Reimeri, Berlín, 1888.

Lesher, J., "Aristotle on Form, Substance, and Universals: A Dilemma", Phronesis, vol. 16, 1971, pp. 169-178.

Diánoia, vol. LV, no. 65 (Noviembre 2010). 
Moraux, P., Der Aristotelismus bei den Griechen von Andronikos bis Alexander von Aphrodisias, vol. III, ed. J. Wiesner, De Gruyter, Berlín, 2001.

Shields, C., Order in Multiplicity: Homonymy in the Philosophy of Aristotle, Oxford University Press, Oxford, 1999.

Simplicio, Simplicius: On Aristotle's Categories 5-6, trad. Frans de Haas y Barrie Fleet, Cornell University Press, Ithaca, 2001.

Ward, J., Aristotle on Homonymy: Dialectic and Science, Cambridge University Press, Cambridge, 2008.

Recibido el 13 de agosto de 2010; aceptado el 7 de octubre de 2010. 